\title{
Review
}

Acta Haematol 2019;142:44-50

Received: December 11, 2018

DOI: $10.1159 / 000496492$

Accepted: January 2, 2019

Published online: April 10, 2019

\section{Iron Deficiency Anemia in Chronic Kidney Disease}

\author{
Anat Gafter-Gvilia, b, d Amir Schechter ${ }^{a}$ Benaya Rozen-Zvii ${ }^{c} d$ \\ ${ }^{a}$ Department of Medicine A, Rabin Medical Center, Beilinson Campus, Petah Tikva, Israel; ${ }^{b}$ Institute of Hematology, \\ Davidoff Cancer Center, Rabin Medical Center, Beilinson Campus, Petah Tikva, Israel; ' Nephrology and Hypertension \\ Unit, Rabin Medical Center, Petah Tikva, Israel; dSackler Faculty of Medicine, Tel Aviv University, Tel Aviv, Israel
}

\section{Keywords}

Iron deficiency $\cdot$ Anemia $\cdot$ Chronic kidney disease $\cdot$ Dialysis

\begin{abstract}
Iron deficiency anemia is a common complication of chronic kidney disease (CKD). CKD patients suffer from both absolute and functional iron deficiency. Absolute iron deficiency is defined by severely reduced or absent iron stores, while functional iron deficiency is defined by adequate iron stores but insufficient iron availability for incorporation into erythroid precursors. This is due to increased levels of hepcidin. Anemia in CKD is associated with an increased risk of morbidity and mortality. The association between anemia and mortality may be related to the severity of anemia. All CKD patients should be screened for anemia during the initial evaluation for CKD. Criteria used to define iron deficiency are different among CKD compared to normal renal function. Among CKD patients, absolute iron deficiency is defined when the transferrin saturation (TSAT) is $\leq 20 \%$ and the serum ferritin concentration is $\leq 100 \mathrm{ng} / \mathrm{mL}$ among predialysis and peritoneal dialysis patients or $\leq 200 \mathrm{ng} / \mathrm{mL}$ among hemodialysis patients. Functional iron deficiency, also known as iron-restricted erythropoiesis, is characterized by TSAT $\leq 20 \%$ and elevated ferritin levels. Iron supplementation is
\end{abstract}

recommended for all CKD patients with anemia. There is general agreement according to guidelines that intravenous (i.v.) iron supplementation is the preferred method for CKD patients on dialysis (CKD stage 5D) and either i.v. or oral iron is recommended for patients with CKD ND (CKD stages 3-5). In this review we discuss the evidence base for these recommendations.

(c) 2019 S. Karger AG, Basel

\section{Pathophysiology of Iron Metabolism in Chronic Kidney Disease}

Iron is a vital element in human metabolism. Due to its unique ability to act both as an electron donor (in its ferrous state) and as an electron acceptor (in its ferric state), iron plays an imperative part in cellular respiration as well as oxygen transport and storage. However, due to its ability to receive and transfer electrons, iron can cause severe oxidative stress and tissue damage [1]. As iron has an essential role in both energy metabolism and damaging potential, its absorption, transfer, and metabolism are tightly regulated. The regulation of iron is done mainly by adjusting absorption [2]. This is due to the fact that the ability of the body to secrete iron is negligible [2].

\section{KARGER}

(c) 2019 S. Karger AG, Basel

E-Mail karger@karger.com

www.karger.com/aha
Anat Gafter-Gvili, MD

Department of Medicine A and Institute of Hematology, Rabin Medical Center Beilinson Campus, Kaplan Street

Petah Tikva 49100 (Israel)

E-Mail anatga2@ clalit.org.il 
Iron is also recycled within the body as senescent red blood cells are phagocytosed by reticuloendothelial macrophages and their iron content is either used for hematopoiesis if needed or stored for further use. Regulation of iron metabolism is mediated, mainly, by hepcidin, a small peptide hormone ( 25 amino acids) which is synthesized and secreted by the liver [3]. Hepcidin prevents iron transport by binding to the iron transporter ferroportin which is located on the basal membrane of enterocytes, reticuloendothelial cells, and hepatocytes. Hepcidin binding causes internalization of ferroportin from the plasma membrane into the cell and its ultimate degradation [4]. As a result, in the presence of hepcidin, iron is not absorbed or recycled from the reticuloendothelial cells and circulating iron levels are reduced. Hepcidin levels are controlled by multiple stimuli including: iron stores [5], hypoxia [6, 7], inflammation [8], and erythropoiesis [9]. Since hepcidin is a small hormone peptide, it is filtered and degraded by the kidney. Hepcidin levels are increased in chronic kidney disease (CKD) and negatively correlated with the glomerular filtration rate (GFR) $[10,11]$. The mechanisms responsible for this phenomenon in $\mathrm{CKD}$ include a reduced renal clearance, increased inflammatory cytokines, and reduced erythropoietin levels [1214].

In addition, CKD patients have an absolute iron deficiency. This can arise from an increased rate of blood loss during dialysis [15]. The frequent phlebotomies, and blood remaining in the dialysis tubing, contribute to iron loss [16]. The high rate of iron loss (1-3 g/year) is also due to gastrointestinal bleeding from the combination of gastritis and platelet dysfunction [17]. This is common in both dialysis- and non-dialysis (ND)-dependent CKD [18]. Decreased gastrointestinal iron absorption and malnutrition contribute as well.

Due to the combination of reduced iron absorption and increased iron losses, iron deficiency is common among CKD patients who are both ND and dialysis dependent.

The following 2 forms of iron deficiency are recognized: absolute (true) iron deficiency and functional iron deficiency. Absolute iron deficiency is defined by severely reduced or absent iron stores in bone marrow, liver, and spleen. Functional iron deficiency is defined by normal or increased total body iron stores which are unavailable for incorporation into erythroid precursors for erythropoiesis [19]. Functional iron deficiency is mainly due to increased levels of hepcidin which reduce the ability to recruit iron stores from reticuloendothelial cells and hepatocytes for erythropoiesis.

Iron Deficiency in CKD

\section{Outcomes of Iron Deficiency Anemia in CKD}

Anemia in CKD has been shown to be associated with an increased risk of morbidity and mortality [20-23]. In a large observational study, 27,998 patients with CKD were followed up for approximately 5.5 years [20]. The authors reported a higher baseline prevalence of anemia in patients who died than in those who survived (as well as a higher prevalence of coronary artery disease, congestive heart failure, and diabetes mellitus). Furthermore, the increase in the prevalence of anemia over the observation period was greatest in those who died despite a shorter period of observation.

The high rates of heart disease and anemia in those who died suggest that anemia accelerates the progression of heart disease and increases the risk of death. However, anemia may be a marker for severity of CKD rather than a causative factor [20].

A retrospective cohort study among patients with incident CKD who had hemoglobin ( $\mathrm{Hb}$ ) measurements, in a large health maintenance organization administrative data set, evaluated 5,885 patients [24]. Anemia was found to be a predictor of excess mortality, excess cardiovascular hospitalizations, and excess end-stage renal disease (ESRD). For those with the most severe anemia $(\mathrm{Hb}<10.5$ $\mathrm{g} / \mathrm{dL}$ ), there was an increased rate of mortality (HR 5.27; 95\% CI 4.37-6.35), cardiovascular hospitalizations (HR 2.18; 95\% CI 1.76-2.70), and ESRD (HR 5.46; 95\% CI $3.38-8.82$ ) when compared to those who were not anemic.

The association between anemia and mortality was also shown to be related to the severity of anemia in a historical prospective cohort of 853 patients with CKD stage 3-5 who were predialysis. $\mathrm{Hb}$ values were collected longitudinally over a median follow-up of about 2 years. A time-averaged $\mathrm{Hb}(<11 \mathrm{~g} / \mathrm{dL})$ was associated with increased mortality (HR 2.06; 95\% CI 1.35-3.13), compared to the group with a time-averaged $\mathrm{Hb}$ of more than $13 \mathrm{~g} /$ $\mathrm{dL}$ [21]. Even those with a time-averaged $\mathrm{Hb}$ of 11-12 g/ dL had a significantly higher HR for mortality (HR 1.8; 95\% CI 1.23-2.63) compared to the group with a timeaveraged $\mathrm{Hb}$ of more than $13 \mathrm{~g} / \mathrm{dL}$. Lower time-averaged $\mathrm{Hb}$ levels also correlated with a statistically significant increased risk in the composite end point of predialysis mortality and ESRD as follows: HR 2.57 (95\% CI 1.853.58) for $\mathrm{Hb}<11 \mathrm{~g} / \mathrm{dL}$, HR 1.97 (95\% CI 1.45-2.66) for $\mathrm{Hb}<12 \mathrm{~g} / \mathrm{dL}$, again, compared with $\mathrm{Hb}>13 \mathrm{~g} / \mathrm{dL}$.

Anemia in CKD may be frequently associated with a reduced quality of life (QoL) [25]. In a study that examined the relationship between Kidney Disease Quality of Life (KDQofL) questionnaire domains and $\mathrm{Hb}$ levels

Acta Haematol 2019;142:44-50

DOI: $10.1159 / 000496492$ 
in 1,200 patients with stage 3,4 , and $5 \mathrm{CKD}$, higher $\mathrm{Hb}$ levels were associated with improved QoL domains of the KDQofL questionnaire. The most dramatic improvements in the various QoL domains occurred between the groups with $\mathrm{Hb}<11 \mathrm{~g} / \mathrm{dL}$ and $\mathrm{Hb}$ of $11-12 \mathrm{~g} /$ dL [25].

\section{Definitions and Diagnosis of Iron Deficiency in CKD Patients}

CKD may be associated with either absolute or functional iron deficiency. Functional iron deficiency may be related to the administration of erythropoiesis-stimulating agents (ESA) which rapidly increases erythropoiesis. In this situation, total body iron stores are adequate, but iron release from stores into the circulation is not rapid enough to provide sufficient iron to support the increased erythropoietic rate driven by the ESA. In addition, in $\mathrm{CKD}$, concomitant anemia of chronic disease (iron-restricted erythropoiesis) is often present, which is related to an underlying inflammatory state [26] and mediated partly by hepcidin, the levels of which were found to be increased in CKD $[10,12]$.

It is difficult to determine whether functional iron deficiency is related to ESA or to anemia of chronic disease with an "inflammatory block" of available iron.

All CKD patients, particularly those with an estimated GFR (eGFR) $<60 \mathrm{~mL} / \mathrm{min} / 1.73 \mathrm{~m}^{2}$, should be screened for anemia on initial evaluation for CKD. Anemia is defined as $\mathrm{Hb}<13 \mathrm{~g} / \mathrm{dL}$ in men and $\mathrm{Hb}<12 \mathrm{~g} / \mathrm{dL}$ in women, according to WHO criteria [27]. These thresholds are accepted by 2012 Kidney Disease: Improving Global Outcomes (KDIGO) guidelines [28]. The European Renal Best Practice (ERBP) position statement suggested adapting these thresholds to the European population [29]. They suggest that a diagnosis of anemia should be made and further evaluation should be undertaken when $\mathrm{Hb}$ concentrations are $<13.5 \mathrm{~g} / \mathrm{dL}$ in adult males $(13.2 \mathrm{~g} / \mathrm{dL}$ in men $>70$ years) and $<12.0 \mathrm{~g} / \mathrm{dL}$ in adult females.

Measurement of the following parameters is commonly used to identify iron deficiency: serum iron, total iron-binding capacity, ferritin, and transferrin saturation (TSAT = plasma iron divided by the total iron-binding capacity $\times 100$ ).

The laboratory criteria used to define iron deficiency and provide indication for treatment are different in CKD compared to normal renal function [30]. In CKD, absolute iron deficiency is likely to be present when the TSAT is $\leq 20 \%$ and the serum ferritin concentration is $\leq 100 \mathrm{ng} /$ $\mathrm{mL}$ among predialysis and peritoneal dialysis (PD) patients or $\leq 200 \mathrm{ng} / \mathrm{mL}$ among patients undergoing hemodialysis. By comparison, with normal kidney function, iron deficiency anemia is typically defined as serum ferritin concentrations $<30 \mathrm{ng} / \mathrm{mL}$.

Functional iron deficiency, both ESA-induced functional deficiency and anemia of chronic disease are usually characterized by TSAT $\leq 20 \%$ and elevated ferritin levels (as high as $800 \mathrm{ng} / \mathrm{mL}$ ) $[29,30]$.

The percentage of hypochromic red blood cells (HRC) and the reticulocyte $\mathrm{Hb}$ content $(\mathrm{CHr})$ estimate the $\mathrm{Hb}$ content of red blood cells rather than the amount of storage iron, providing a snapshot of recent iron availability for $\mathrm{Hb}$ synthesis which acts as a sensitive indicator of functional iron deficiency and are possibly better than TSAT and ferritin in predicting whether or not there will be a response to iron administration. A meta-analysis performed for the 2016 UK-based National Institute for Health and Care Excellence (NICE) guidelines demonstrated that HRC $>6 \%$ predicted who would respond to iron (as well as TSAT $<20 \%$ and ferritin $<100 \mathrm{ng} / \mathrm{mL}$ ) [31]. NICE guidelines recommend that iron deficiency be diagnosed using HRC or CHr. The cut-offs recommended for diagnosing iron deficiency are $\mathrm{CHr}<29 \mathrm{pg}$ and HRC $>6 \%$. Importantly, neither the percentage of HRC nor $\mathrm{CHr}$ differentiate between functional and absolute iron deficiency.

According to the KDIGO guidelines, regular testing for anemia is not routinely recommended [28]. The $\mathrm{Hb}$ concentration should be measured only when clinically indicated, or at least annually in CKD stage 3, twice per year in CKD stage 4-5 ND cases, or every 3 months in $\mathrm{CKD}$ stage $5 \mathrm{D}$ (dialysis). There is no specific recommendation for transplanted patients.

In CKD with anemia not being treated with an ESA, the recommendation is to measure the $\mathrm{Hb}$ concentration only when clinically indicated, at least every 3 months in CKD stage 3-5 ND and CKD stage $5 \mathrm{PD}$, and monthly in CKD stage 5 hemodialysis.

\section{Treatment of Iron Deficiency Anemia in CKD ND}

Iron supplementation can be administered either orally or intravenously (i.v.). Oral iron is less expensive and easier to administer. However, i.v. iron enables the administration of larger doses of iron rapidly and is better tolerated [32]. i.v. iron is superior to oral iron in achieving a sustained $\mathrm{Hb}$ response, reducing the need for 
blood transfusions and improving QOL in CKD [29, 33, 34].

The KDIGO, the National Kidney Foundation-Kidney Disease Outcomes Quality Initiative (KDOQI), and the anemia working group of the ERBP $[28,29,33]$ recommend iron supplementation in CKD with anemia and absolute or functional iron deficiency. While cut-off ferritin and TSAT levels for iron replacement initiation vary among these guidelines, there is general agreement on i.v. iron supplementation for CKD on dialysis (CKD stage 5D) and either i.v. or oral iron for CKD ND (CKD stages 3-5).

According to KDIGO guidelines, for adults with CKD and anemia who are not on iron or ESA therapy, a trial of i.v. iron is suggested (or in CKD ND alternatively a 1- to 3 -month trial of oral iron therapy). This is suggested if an increase in $\mathrm{Hb}$ concentration without starting ESA treatment is desired (based on symptoms and overall clinical goals, including avoidance of transfusion, improvement of anemia-related symptoms, and after exclusion of active infection) and TSAT is $\leq 30 \%$ and ferritin is $\leq 500 \mathrm{ng} / \mathrm{mL}$ (grade of recommendation: $2 \mathrm{C}$ ). For adults with CKD on ESA who are not receiving iron supplementation, a trial of i.v. iron is recommended (or in CKD ND alternatively a 1- to 3-month trial of oral iron therapy) if an increase in $\mathrm{Hb}$ concentration is desired or a decrease in ESA dose is desired and TSAT is $\leq 30 \%$ and ferritin is $\leq 500 \mathrm{ng} / \mathrm{mL}$ (2C) [28].

The KDOQI commentary group reviewed these KDIGO recommendations and suggested that they may be too cautious regarding the use of i.v. iron [34].

The EBRP anemia group position statement suggests for the European population with CKD that adults with CKD with anemia who are not on iron or ESA therapy receive iron therapy. Iron should be either frontline oral iron, if tolerated, in ND-CKD, especially in CKD stage $2-3$, or in PD with an immediate switch to the i.v. route if not. This is suggested if there is an absolute iron deficiency (TSAT $<20 \%$ and serum ferritin $<100 \mathrm{ng} / \mathrm{mL}$ ) or if an increase in $\mathrm{Hb}$ concentration without starting ESA treatment is desired and TSAT is $<25 \%$ and ferritin is $<200 \mathrm{ng} / \mathrm{mL}$ in ND-CKD and ferritin is $<300 \mathrm{ng} / \mathrm{mL}$ in dialysis. The limit of TSAT of $30 \%$ and that of serum ferritin of $500 \mathrm{ng} / \mathrm{mL}$ should not be intentionally exceeded [29].

The NICE guidelines suggest using oral iron for individuals who are not on ESA and offering i.v. iron to those who do not tolerate oral therapy or do not reach targets within 3 months. For those receiving ESA the i.v. route is preferred [31].
At the time of the KDIGO guideline publication, data showing a greater efficacy of i.v. iron compared to oral iron in CKD ND were more limited. Since then, numerous randomized controlled trials (RCT) favoring i.v. iron for the treatment of iron deficiency in CKD have been published.

In a meta-analysis of RCT comparing i.v. versus oral iron supplementation for the treatment of anemia in CKD conducted by our group in 2008 , thirteen trials were included but only 6 were CKD ND trials [35]. With CKD, there was a small but significant difference in $\mathrm{Hb}$ concentration favoring the i.v. iron group. This meta-analysis was updated in 2016 [36], with 24 trials included, 13 of which were in the CKD stage 3-5 ND population. The 13 CKD stage 3-5 ND trials were heterogeneous with regard to inclusion criteria. The $\mathrm{Hb}$ threshold criteria ranged from $<8$ to $<12 \mathrm{~g} / \mathrm{dL}$, the TSAT threshold criteria was either $<20$ or 25 or $30 \%$ and the ferritin threshold ranged from $<100$ to $<600 \mathrm{ng} / \mathrm{mL}$. Subsequently, trials of both functional and absolute iron deficiency were included. Accordingly, the baseline hematologic parameters varied: $\mathrm{Hb}$ concentrations varied from $5.8 \pm 0.6$ to $11.9 \pm 0.7 \mathrm{~g} /$ $\mathrm{dL}$, baseline ferritin levels varied from $57.3 \pm 48.6$ to 345 $\pm 273 \mathrm{ng} / \mathrm{mL}$, and baseline TSAT varied from $15.4 \pm 5.5$ to $63.6 \pm 11.1 \%$.

The total administered i.v. iron dose reported in the trials ranged from 600 to $3,600 \mathrm{mg}$, with a median of 1,000 $\mathrm{mg}$. The i.v. iron schedule varied between trials. The most common schedules was a dose of 100-200 mg every 1-2 weeks for the older iron formulations (iron sucrose and iron gluconate) or 500-1,000 mg 1-2 times for the newer iron preparations (ferric carboxymaltose and ferrumoxytol). The results of the meta-analysis of 5 trials reported that when CKD ND was treated with i.v. iron, achievement of an $\mathrm{Hb}$ response $>1 \mathrm{~g} / \mathrm{dL}$, with risk ratios (RR) of 1.61 (95\% CI 1.39-1.87), was more likely to occur. Benefits from i.v. iron across all of the examined subgroups were observed, according to baseline $\mathrm{Hb}(<10$ or $>10 \mathrm{~g} /$ $\mathrm{dL})$, baseline ferritin $(<100$ or $>100 \mathrm{ng} / \mathrm{mL})$, and baseline TSAT $(<15 \%$ or $>15 \%)$ values. Subgroup analysis showed that the benefit of i.v. iron was similar for the different iron formulations used (iron sucrose, ferric carboxymaltose, and ferrumoxytol).

The safety analysis was pooled for all trials (CKD and dialysis). All-cause mortality did not differ between those who received i.v. versus oral iron replacement (RR 0.94; 95\% CI $0.55-1.63$; 16 trials; 2,612 patients). There was also no difference in the rate of any adverse events, serious adverse events, or infections [36]. 
Similar safety results were shown in a recent comprehensive meta-analysis which included 103 trials and 14,434 patients, in which i.v. iron was compared to oral iron in many different clinical settings. i.v. iron has a safety profile comparable to that of oral iron, with the same rate of serious adverse events and bacterial infections, more infusion reactions, and fewer gastrointestinal side effects [37].

Observational analyses in CKD ND have also suggested potential benefits of initiating i.v. iron therapy prior to dialysis onset. A prospective study, based on the Taiwan National Health Insurance Research Database, included 31,971 adult patients who had a serum creatinine level $>6 \mathrm{mg} / \mathrm{dL}$ and a hematocrit level $<28 \%$ and who were treated with ESA. It was found that patients who were treated with ESA and initiated i.v. iron supplementation had a lower risk of all-cause death than those who did not receive iron. In this study, the risk of hospitalization was also lower, although the risk of faster progression to ESRD was higher [38].

Thus, we believe that the benefit of i.v. iron outweighs the risks in CKD, and i.v. iron is the preferred route of administration in ND-CKD.

\section{Treatment of Iron Deficiency Anemia in Dialysis CKD-5D}

CKD patients who are treated with dialysis are especially vulnerable to iron deficiency anemia, due to blood retained in the dialysis machine and tubes (as high as up $2 \mathrm{~g}$ of iron per year) $[39,40]$.

In contrast to CKD stage $3-5$, for which KDIGO clinical practice guidelines allow a trial of oral iron before starting i.v. iron, these guidelines are very clear regarding therapy for CKD-5D, stating that patients with CKD-5D with anemia should be treated with i.v. iron [28]. This unequivocal recommendation was adopted by the KDOQI [33], the NICE [31, 41], and the EBRP position statement [29] and it was based on several RCT and a metaanalysis involving hemodialysis patients in whom a greater increase in $\mathrm{Hb}$ was achieved with i.v. iron compared to oral iron, regardless of ESA treatment $[28,35$, 36]. The convenience of having a venous access for i.v. iron treatment further supports the choice of an i.v. route.

The guidelines were published in 2012 and 2013, and since then additional studies addressing this subject have been conducted and published, further supporting the use of i.v. iron in CKD-5D. In the meta-analysis by our group, which was previously mentioned, 11 trials with
818 CKD-5D patients (in addition to another 2,369 patients with CKD stage $3-5$ ) were included. It showed that i.v. iron treatment is more likely to achieve a response $>1$ $\mathrm{g} / \mathrm{dL} \mathrm{Hb}$. There were no significant differences regarding mortality or adverse effects [36].

Data regarding patients undergoing PD (CKD-5PD) are scarce and therefore there are no one clear recommendations. KDIGO considers the available evidence strong enough to prove the superiority of the i.v. route in this population, whereas KDIGO and EBRP suggest an initial oral treatment [29].

The recommended treatment is an initial loading dose of $1,000 \mathrm{mg}$ of i.v. iron (with repeated loading doses until the $\mathrm{Hb}$ level rises), followed by maintenance treatment which consists of smaller, regularly administrated, i.v. iron.

When the ferritin level exceeds $500-800 \mathrm{ng} / \mathrm{mL}$, the safety of further iron treatment is still a matter of debate due to the lack of reliable data. Most studies were small and retrospective, yet they showed an association with increased mortality [42]. Other studies, including an RCT of CKD hemodialysis (CKD5-HD) patients (i.e., the DRIVE study [43]), did not show that effect. Current KDIGO guidelines recommend not administering additional i.v. iron for ferritin levels consistently $>500 \mathrm{ng} / \mathrm{mL}$.

Most recently, Macdougall el al. [44] conducted a prospective RCT (the PIVOTAL trial) which included 2,141 CKD5-HD patients, who were randomized to either high-dose i.v. iron (400 mg monthly, as long as the ferritin level was $<700 \mathrm{ng} / \mathrm{mL}$ and TSAT was $<40 \%$ ) versus a low dose (0-400 mg, only when the ferritin level was $<200 \mathrm{ng} / \mathrm{mL}$ or TSAT $<20 \%)$. The cumulative doses of i.v. iron were greater in the high-dose group than in the low-dose group. At 1 year, those in the high-dose group had received a median of $2,000 \mathrm{mg}(95 \%$ CI $1,900-2,100)$ more iron than those in the low-dose group. The median monthly dose of iron was $264 \mathrm{mg}$ (IQR 200-336) in the high-dose group compared to $145 \mathrm{mg}$ (IQR 100-190) in the low-dose group. Thus, patients in the high-dose group received approximately twice the amount of iron as those in the low-dose group over the first year of the trial and $83.5 \%$ more iron per month over the course of the trial.

The results show that the proactively administered, high-dose iron was noninferior to the use of a low-dose i.v. iron regimen administered reactively and was not associated with a higher risk of death, major adverse cardiovascular events, or infection. Moreover, high-dose iron allowed a decrease in ESA dosages, the number of blood transfusions, and hospitalizations for heart failure.
Gafter-Gvili/Schechter/Rozen-Zvi 
In conclusion, iron deficiency anemia is a common complication of CKD patients. Absolute iron deficiency in CKD patients is commonly defined when TSAT is $\leq 20 \%$ and the serum ferritin concentration is $\leq 100 \mathrm{ng} /$ $\mathrm{mL}$ among predialysis and PD patients or $\leq 200 \mathrm{ng} / \mathrm{mL}$ among hemodialysis patients. Guidelines suggest treat- ment with i.v. iron in patients on dialysis and either i.v. iron or a trial with oral and then i.v. iron in non-CKD patients. This is based on RCT and meta-analyses demonstrating efficacy with i.v. iron in terms of hematopoietic response and safety.

\section{References}

1 Zager RA. Parenteral iron compounds: potent oxidants but mainstays of anemia management in chronic renal disease. Clin J Am Soc Nephrol. 2006 Sep;1 Suppl 1:S24-31.

2 Hentze MW, Muckenthaler MU, Galy B, Camaschella C. Two to tango: regulation of Mammalian iron metabolism. Cell. 2010 Jul; 142(1):24-38.

3 Nicolas G, Bennoun M, Devaux I, Beaumont C, Grandchamp B, Kahn A, et al. Lack of hepcidin gene expression and severe tissue iron overload in upstream stimulatory factor 2 (USF2) knockout mice. Proc Natl Acad Sci USA. 2001 Jul;98(15):8780-5.

4 Nemeth E, Tuttle MS, Powelson J, Vaughn MB, Donovan A, Ward DM, et al. Hepcidin regulates cellular iron efflux by binding to ferroportin and inducing its internalization. Science. 2004 Dec;306(5704):2090-3.

5 Mazur A, Feillet-Coudray C, Romier B, Bayle D, Gueux E, Ruivard M, et al. Dietary iron regulates hepatic hepcidin 1 and 2 mRNAs in mice. Metabolism. 2003 Oct;52(10): 1229-31.

6 Shah YM, Xie L. Hypoxia-inducible factors link iron homeostasis and erythropoiesis. Gastroenterology. 2014 Mar;146(3):630-42.

7 Silvestri L, Pagani A, Camaschella C. Furinmediated release of soluble hemojuvelin: a new link between hypoxia and iron homeostasis. Blood. 2008 Jan;111(2):924-31.

8 Nemeth E, Valore EV, Territo M, Schiller G, Lichtenstein A, Ganz T. Hepcidin, a putative mediator of anemia of inflammation, is a type II acute-phase protein. Blood. 2003 Apr; 101(7):2461-3

9 Nicolas G, Chauvet C, Viatte L, Danan JL, Bigard X, Devaux I, et al. The gene encoding the iron regulatory peptide hepcidin is regulated by anemia, hypoxia, and inflammation. J Clin Invest. 2002 Oct;110(7):1037-44.

10 Ashby DR, Gale DP, Busbridge M, Murphy KG, Duncan ND, Cairns TD, et al. Plasma hepcidin levels are elevated but responsive to erythropoietin therapy in renal disease. Kidney Int. 2009 May;75(9):976-81.

11 Zaritsky J, Young B, Wang HJ, Westerman M, Olbina G, Nemeth E, et al. Hepcidin-a potential novel biomarker for iron status in chronic kidney disease. Clin J Am Soc Nephrol. 2009 Jun;4(6):1051-6.
12 Babitt JL, Lin HY. Molecular mechanisms of hepcidin regulation: implications for the anemia of CKD. Am J Kidney Dis. 2010 Apr; 55(4):726-41.

13 Kato A, Tsuji T, Luo J, Sakao Y, Yasuda H, Hishida A. Association of prohepcidin and hepcidin-25 with erythropoietin response and ferritin in hemodialysis patients. Am J Nephrol. 2008;28(1):115-21.

14 van der Weerd NC, Grooteman MP, Bots ML, van den Dorpel MA, den Hoedt CH, Mazairac $\mathrm{AH}$, et al.; CONTRAST Investigators. Hepcidin-25 in chronic hemodialysis patients is related to residual kidney function and not to treatment with erythropoiesis stimulating agents. PLoS One. 2012;7(7):e39783.

15 Babitt JL, Lin HY. Mechanisms of anemia in CKD. J Am Soc Nephrol. 2012 Oct;23(10): 1631-4.

16 Besarab A, Ayyoub F. Anemia in renal disease. In: Schrier RW, editor. Diseases of the Kidney and Urinary Tract. Philadelphia: Lippincott Williams and Wilkins; 2007. pp. 2406-30.

17 Yang JY, Lee TC, Montez-Rath ME, Paik J, Chertow GM, Desai M, et al. Trends in acute nonvariceal upper gastrointestinal bleeding in dialysis patients. J Am Soc Nephrol. 2012 Mar;23(3):495-506.

18 Liang CC, Wang SM, Kuo HL, Chang CT, Liu $\mathrm{JH}$, Lin $\mathrm{HH}$, et al. Upper gastrointestinal bleeding in patients with CKD. Clin J Am Soc Nephrol. 2014 Aug;9(8):1354-9.

19 Auerbach M, Adamson JW. How we diagnose and treat iron deficiency anemia. Am J Hematol. 2016 Jan;91(1):31-8.

20 Keith DS, Nichols GA, Gullion CM, Brown JB, Smith DH. Longitudinal follow-up and outcomes among a population with chronic kidney disease in a large managed care organization. Arch Intern Med. 2004 Mar;164(6): 659-63.

21 Kovesdy CP, Trivedi BK, Kalantar-Zadeh K, Anderson JE. Association of anemia with outcomes in men with moderate and severe chronic kidney disease. Kidney Int. 2006 Feb; 69(3):560-4.

22 Regidor DL, Kopple JD, Kovesdy CP, Kilpatrick RD, McAllister CJ, Aronovitz J, et al. Associations between changes in hemoglobin and administered erythropoiesis-stimulating agent and survival in hemodialysis patients. J Am Soc Nephrol. 2006 Apr;17(4):1181-91.
23 Singh N, Agarwal AK. Pumping iron: revisiting risks, benefits and strategies in treatment of iron deficiency in end-stage renal disease. Clin Nephrol. 2012 Mar;77(3):188-94.

24 Thorp ML, Johnson ES, Yang X, Petrik AF, Platt R, Smith DH. Effect of anaemia on mortality, cardiovascular hospitalizations and end-stage renal disease among patients with chronic kidney disease. Nephrology (Carlton). 2009 Apr;14(2):240-6.

25 Finkelstein FO, Story K, Firanek C, Mendelssohn D, Barre P, Takano T, et al. Health-related quality of life and hemoglobin levels in chronic kidney disease patients. Clin J Am Soc Nephrol. 2009 Jan;4(1):33-8.

26 Rambod M, Kovesdy CP, Kalantar-Zadeh K. Combined high serum ferritin and low iron saturation in hemodialysis patients: the role of inflammation. Clin J Am Soc Nephrol. 2008 Nov;3(6):1691-701.

27 World Health Organization technical report series No. 405: nutritional anemias - report of a WHO Scientific Group. Geneva: WHO; 1968.

28 Kidney Disease: Improving Global Outcomes (KDIGO) Anemia Work Group - KDIGO clinical practice guideline for anemia in chronic kidney disease. Kidney Int Suppl. 2012;2(1):279-335

29 Locatelli F, Bárány P, Covic A, De Francisco A, Del Vecchio L, Goldsmith D, et al.; ERAEDTA ERBP Advisory Board. Kidney Disease: Improving Global Outcomes guidelines on anaemia management in chronic kidney disease: a European Renal Best Practice position statement. Nephrol Dial Transplant. 2013 Jun;28(6):1346-59.

30 Cappellini MD, Comin-Colet J, de Francisco A, Dignass A, Doehner W, Lam CS, et al.; IRON CORE Group. Iron deficiency across chronic inflammatory conditions: international expert opinion on definition, diagnosis, and management. Am J Hematol. 2017 Oct; 92(10):1068-78.

31 Ratcliffe LE, Thomas W, Glen J, Padhi S, Pordes BA, Wonderling D, et al. Diagnosis and Management of Iron Deficiency in CKD: A Summary of the NICE Guideline Recommendations and Their Rationale. Am J Kidney Dis. 2016 Apr;67(4):548-58. 
32 Tolkien Z, Stecher L, Mander AP, Pereira DI, Powell JJ. Ferrous sulfate supplementation causes significant gastrointestinal side-effects in adults: a systematic review and meta-analysis. PLoS One. 2015 Feb;10(2):e0117383.

33 KDOQI. KDOQI clinical practice guideline and clinical practice recommendations for anemia in chronic kidney disease: 2007 update of hemoglobin target. Am J Kidney Dis. 2007 Sep;50(3):471-530.

34 Kliger AS, Foley RN, Goldfarb DS, Goldstein SL, Johansen K, Singh A, et al. KDOQI US commentary on the 2012 KDIGO Clinical Practice Guideline for Anemia in CKD. Am J Kidney Dis. 2013 Nov;62(5):849-59.

35 Rozen-Zvi B, Gafter-Gvili A, Paul M, Leibovici L, Shpilberg O, Gafter U. Intravenous versus oral iron supplementation for the treatment of anemia in CKD: systematic review and meta-analysis. Am J Kidney Dis. 2008 Nov;52(5):897-906.
36 Shepshelovich D, Rozen-Zvi B, Avni T, Gafter U, Gafter-Gvili A. Intravenous Versus Oral Iron Supplementation for the Treatment of Anemia in CKD: An Updated Systematic Review and Meta-analysis. Am J Kidney Dis. 2016 Nov;68(5):677-90.

37 Avni T, Bieber A, Grossman A, Green H, Leibovici L, Gafter-Gvili A. The safety of intravenous iron preparations: systematic review and meta-analysis. Mayo Clin Proc. 2015 Jan; 90(1):12-23.

38 Kuo KL, Hung SC, Liu JS, Chang YK, Hsu CC, Tarng DC. Iron supplementation associates with low mortality in pre-dialyzed advanced chronic kidney disease patients receiving erythropoiesis-stimulating agents: a nationwide database analysis. Nephrol Dial Transplant. 2015 Sep;30(9):1518-25.

39 Sargent JA, Acchiardo SR. Iron requirements in hemodialysis. Blood Purif. 2004;22(1):11223.

40 Schaefer RM, Schaefer L. Iron monitoring and supplementation: how do we achieve the best results? Nephrol Dial Transplant. 1998; 13(90002 Suppl 2):9-12.
41 National Clinical Guideline Centre. Anaemia management in chronic kidney disease: update 2015. NICE guideline 8. National Institute for Health and Care Excellence (NICE). London; National Clinical Guideline Centre: 2015.

42 Kalantar-Zadeh K, Don BR, Rodriguez RA, Humphreys MH. Serum ferritin is a marker of morbidity and mortality in hemodialysis patients. Am J Kidney Dis. 2001 Mar;37(3):56472.

43 Coyne DW, Kapoian T, Suki W, Singh AK, Moran JE, Dahl NV, et al.; DRIVE Study Group. Ferric gluconate is highly efficacious in anemic hemodialysis patients with high serum ferritin and low transferrin saturation: results of the Dialysis Patients' Response to IV Iron with Elevated Ferritin (DRIVE) Study. J Am Soc Nephrol. 2007 Mar;18(3):975-84.

44 Macdougall IC, White C, Anker SD, Bhandari S, Farrington K, Kalra PA, et al.; PIVOTAL Investigators and Committees. Intravenous Iron in Patients Undergoing Maintenance Hemodialysis. N Engl J Med. 2018 Oct;NEJMoa1810742. 